\title{
CASAS, ESPAÇOS PÚBLICOS E PARQUES - O CASO ENTRE OS MACACOS- PREGO E A CIDADE EM MARINGÁ
}

\author{
Eliane Sebeika Rapchan ${ }^{1}$
}

\section{Humanos e não-humanos: relações múltiplas}

As reflexões contemporâneas sobre algumas das facetas das relações entre humanos e não-humanos, particularmente em relação a outros animais, especialmente os primatas não-humanos, revela certas analogias esperadas, mas desconfortáveis, quando colocadas em termos espaço-temporais. Dentre as muitas analogias possíveis, vale enfatizar ao menos três.

Uma delas, de forte caráter etnocêntrico, aproxima, por semelhança, populações tribais e rurais a primatas não-humanos em relação a atributos de valor estético, moral ou comportamental e se manifestou fortemente na filosofia, na ciência e nas artes até, pelo menos, o início do século XX (Corbey \& Theunissen, 1995). A outra sinaliza a construção de uma dupla alteridade que se expressou tanto em relação às populações humanas quanto em relação a outras espécies. Nesse contexto, foram classificados tanto os humanos que, por bem ou por mal, entraram em contato com europeus e foram sendo dolorosamente integrados, nos últimos 500 anos, à concepções mais universalistas de humanidade; quanto os representantes dos primatas não-humanos e de outras espécies que foram sendo aproximados dos humanos em relação a atributos como sociabilidade, inteligência, pertencimento à condição de pessoa e capacidade de produzir cultura como características reconhecidamente comparáveis às humanas (Asquith, 2011; Ingold, 1994; Rapchan, 2005, 2010; Rapchan \& Neves, 2005; Stanford, 2001).

Por fim, há o segmento que indica uma tendência contemporânea à valorização da pluralidade das culturas humanas e da diversidade da vida animal (doméstica, selvagem, silvestre) desde que isso não afete interesses ou valores dominantes. É uma espécie de panuniversalismo nominal que ainda precisa reconhecer e lidar com os conflitos advindos das

\footnotetext{
${ }^{1}$ Universidade Estadual de Maringá, Brasil.
} 
sobreposições entre povos, animais, espaços e direitos (Beckert, 2003; Santos, 2002; Mendonça et al. 2011; Segato, 2006; Ricardo, 2004; Felipe, 2009).

Assim, de modo semelhante às reações etnocêntricas frequentemente verificadas nas interações entre culturas humanas é possível reconhecer, nas relações entre humanos e nãohumanos, nesse caso os primatas não-humanos, movimentos de auto-explicação e de autoafirmação pontuados por sucessões de reações antagônicas de atração e repulsa, identificação e diferenciação (Corbey, Theunissen, 1995). O direito (Cavalieri, Singer, 1995), a política (Haraway, 1991), a ciência (Latour, 2000), a arte, os mitos e as fábulas (Warner, 1999, 1996) são expressões vivas e atualizadas disso.

Nessa direção, em décadas recentes, a antropologia tem expressado uma sensibilidade cada vez mais refinada frente às relações entre humanos e não-humanos e tem assumido um papel de destaque nas ciências sociais à medida que tem se constituído como uma das áreas do conhecimento que mais tem contribuído com a revisão das definições sobre as relações entre humanos e animais não-humanos e, consequentemente, com a elaboração dos processos contemporâneos de redefinição do que seriam humanidade (Ingold, 1994) e animalidade (Ingold, 1994).

Desde interações simbólicas e afetivas até as diversas formas de relações instrumentais, as análises sobre as relações entre humanos e animais são orientadas por saberes e conhecimentos dirigidos à sua classificação, equacionamento e compreensão. Assim, enquanto o modelo cartesiano do animal-máquina sugere a coisificação ou, pelo menos, a restrição da condição animal às funções de utilidade para os humanos; modelos relacionais ou sintéticos sugerem possibilidades que escapam, inclusive, dos contrastes marcantes definidos a partir dos dualismos modernos (Ingold, 2015).

O que se pretende aqui é apresentar elementos que favoreçam a reflexão sobre as relações entre humanos e não-humanos, especificamente, os macacos-prego no contexto urbano de uma cidade de porte médio, Maringá, localizada no noroeste do Paraná - Brasil. Tal proposição implica também em, simultaneamente, propor uma reflexão antropológica sobre humanos e não-humanos que coloca o espaço e a paisagem como elementos centrais e constitutivos dessas relações. Assim, o exercício etnográfico enfatiza a constituição destes coletivos híbridos formados por humanos, macacos-prego e espaços cujas relações são elaboradas a partir de interações e conflitos. 
Esses coletivos são, desse modo, observados a partir de uma relação com a paisagem tomando-a não como pano de fundo, mas como elemento constitutivo, essencial e fundante das relações entre humanos e animais. Aliás, indo além, a própria paisagem deve ser considerada como central nas interações entre humanos e macacos-prego dado que o próprio ponto de partida dessa proposição é diluir o enfoque exclusivo sobre o humano no que diz respeito à construção da sociedade e da sociabilidade e distribuí-lo pelo entorno frequentemente esquecido, subtraído ou subvalorizado.

Assim, a paisagem não é considerada aqui exclusivamente como um lugar onde se dão as relações sociais, mas como um fator que modula e é modulado a partir dessas relações de modo a não ser coadjuvante, mas protagonista. Ou seja, tanto o comportamento quanto a informação (Ingold, 2001) são encarados como apenas a ponta do iceberg dos mundos que pretendemos conhecer.

A partir desse mesmo referencial, pretendemos considerar os macacos-prego como elementos que favorecem a problematização das classificações que, a cada geração intelectual definem, por exemplo, os animais como aqueles a quem faltam os atributos humanos ao mesmo tempo em que reconhecem que seríamos melhores se fossemos mais capazes de nos reconhecer como animais (Ingold, 1994). Desse modo, queremos fazer emergir complexidades e escalas, para pensar sobre humanos, macacos e paisagens não como elementos radicalmente distintos, mas como entidades complementares, reconhecendo suas respectivas singularidades e, ainda assim, promovendo assim "conexões parciais" (Strathern, 2005).

\section{Identificando relações entre seres e lugares}

Maringá é um jovem município do noroeste do estado do Paraná cuja história está fortemente associada à expansão das lavouras de café do estado de São Paulo (Priori et al., 2012). Fundada há quase setenta anos é uma cidade de porte médio com uma população de aproximadamente 403.063 habitantes segundo o censo de 2015 (IBGE). Um dos traços particulares e impactantes dessa cidade é a presença significativa de áreas verdes, apesar de sua distribuição desigual pela área do município e dos sérios problemas relacionados aos cuidados e manutenção (Bovo, 2009). 
Maringá foi planejada a partir do conceito de cidade jardim do britânico Ebenezer Howard (Verri, 2001) caracterizado por vias planejadas e intensamente arborizadas. A expansão do plano urbano da cidade não acompanhou seu projeto inicial e, desse modo, verificam-se fortes contrastes entre a concentração de árvores no centro e nas zonas contíguas em detrimento dos outros bairros.

Ao mesmo tempo, segundo dados publicados no site da Secretaria do Meio Ambiente $^{2}$, a cidade possui dezessete bosques além de uma extensa rede de áreas de conservação de fundos de vale. As áreas verdes da cidade habitadas por macacos-prego são o Parque do Ingá, o Bosque dos Pioneiros (Bosque II) e o Parque Borba Gato.

O Parque do Ingá fica no centro da cidade. Possui 47,3 hectares de mata natural remanescente e é uma Área de Proteção Permanente (APP) desde 1991. Esse parque possui pistas de corrida e calçadas que cercam todo o seu perímetro e é também aberto à visitação. A suspeita de infecção dos macacos-prego por febre amarela levou as autoridades a fecharem o parque para visitação pública entre 2009 e 2011. É habitado por algumas espécies de aves, répteis e mamíferos selvagens, entre eles, o pequeno sagui (Callithrix). Ali moram também alguns animais cativos como um pequeno grupo de macacos-prego.

O Parque dos Pioneiros também se localiza na região central da cidade. Sua área total corresponde a aproximadamente 59 hectares. Pertence à Companhia de Terras do Norte do Paraná e, apesar de estar fechado à visitação pública, esse parque também é cercado por pistas e calçadas muito frequentadas por atletas, turistas e caminhantes, do mesmo modo que o Parque do Ingá.

Por fim, o Parque Borba Gato, localizado na região oeste da cidade, é uma Unidade de Conservação (UC) com $76.540 \mathrm{~m} 2$ de extensão. Está fechado à visitação pública desde 2004 por suspeita de ser um centro difusor de leishmaniose no município. Os três parques habitados por macacos-prego estão cercados por ocupações humanas, contudo, esse é o único localizado na periferia da cidade. Não possui boa infraestrutura para esporte e lazer em seu perímetro externo, ao contrário dos outros dois, e figura na imprensa como local bonito, mas insalubre com registros de macacos que reviram o lixo da vizinhança e denúncias de deposição de lixo e entulho em suas dependências. Segundo matéria publicada na Gazeta do Povo em 19/05/2010: “O Recanto Borba Gato, fechado há seis

\footnotetext{
${ }^{2}$ http://www2.maringa.pr.gov.br/meioambiente/
} 
anos, virou um problema para os vizinhos, pois os macacos que vivem no local reviram o lixo em torno do parque a procura de comida".

Assim, esses três parques compartilham, além das extensas áreas verdes e dos macacos que as habitam, o fato de estarem incrustrados na área urbana da cidade. Cercados por avenidas asfaltadas e calçadas esses parques são áreas contíguas às habitações humanas. Ou seja, aos macacos-prego basta transpor os muros dos parques e atravessar pistas de corrida e avenidas asfaltadas para chegar a casas, comércio, serviços e escolas.

Em termos gerais, o convívio e a interação entre humanos e macacos-prego ocorre em contextos variados. Esta proposição visa enfocar relações inter-espécies, a fim de analisá-las sob enfoque inspirado nas projeções e modulações de Strathern (2014). A estratégia é enfatizar tanto a perspectiva do convívio cotidiano no quintal das casas, nos parques ou nos pátios das escolas quanto a perspectiva da imprensa que registrou as relações entre humanos e macacos enfatizando os riscos do contato com os macacos-prego e alertando a população humana sobre os riscos de doenças e agressões supostamente vindas dos animais.

Há duas perspectivas elucidativas dessas relações. Em uma delas, os humanos se colocam como agentes da prestação de serviços ou da busca do lazer. Eles se deslocam em direção aos espaços de vivência dos macacos e esperam encontrá-los. Funcionários dos órgãos públicos fazem isso para levar alimento e verificar condições gerais de saúde e segurança dos animais e muitos são capazes de se encantar com comportamentos ou reações dos animais. Visitantes dos parques e atletas vão aos lugares onde estão o macaco para vê-los ou encaram encontros fortuitos como um adicional ao seu lazer e relaxamento. No máximo, circundam os espaços onde estão concentrados ou evitam-nos. Tais atitudes, recorrentes nesses casos, parecem se justificar pela constatação que os encontros se estabelecem a partir de demandas humanas em relação ao contato com os macacos. É como se as situações controladas pelos humanos favorecessem a empatia e mesmo o altruísmo em relação aos macacos.

$\mathrm{Na}$ outra perspectiva, entretanto, os humanos não controlam as situações, nem os momentos de início e de fim dos contatos. Em contextos de vizinhança os macacos-prego decidem quando saem das áreas verdes onde habitam subindo e pulando os muros e cercas, atravessam largas avenidas e entram em quintais, casas, pesqueiros e pátios escolares 
gerando reações de conflito e de competição. Nessas situações, os humanos se percebem em contato com os macacos-prego sem, no entanto, terem feito essa escolha. Animais que agarram rapidamente objetos, peças de roupa ou comida e desaparecem rapidamente são chamados de ladrões ou invasores, em que pese o fato de alguns moradores dos arredores, principalmente os mais antigos, se encantarem com o contato tão próximo com os macacos e mesmo deixarem frutas não colhidas nas mangueiras ou em fruteiras colocadas nas janelas abertas de suas casas térreas.

Esses coletivos híbridos (Lestel, 2008), constituídos a partir do agrupamento de elementos ativos, tanto humanos quanto não-humanos são potencialmente dinâmicos Sendo assim, apesar de o fluxo de comunicação entre humanos ser potencialmente mais intenso, os animais não são considerados elementos potencialmente passivos nessas relações. Desse modo, associações, sentimentos, conflitos e antropomorfização são aspectos muito evidentes na observação, mas não são mais importantes que outros fenômenos tais como comportamentos ou reações verificáveis tanto em relação a uns quanto outros.

Assim, a problemática que reúne humanos, macacos-prego, parques e seus territórios contíguos reconhece que estão todos intimamente relacionados de modo a constituírem contextos que agregam vivos e não-vivos em espaços físicos e espaços simbólicos repousa no reconhecimento de que esses coletivos definem espaços de sociabilidade intensa entre humanos e não-humanos (animais, essencialmente, mas não exclusivamente) os quais, por sua vez, envolvem fortes emoções (de atração e de repúdio) e valores profundos (como vida e morte, admiração e competição, identificação e repulsa).

Esses espaços podem ser vistos como lugares de adensamento de sociabilidades na paisagem (de Certeau et al., 1997) onde se definem relações que possuem características singulares e comuns, ou seja, são lugares de sociabilidade intensa entre humanos e macacos. Assim, enquanto o parque e seus arredores são, para os macacos-prego, espaços contínuos que podem ser explorados, apesar de apresentarem elementos um tanto quanto diversos; para os humanos, os domínios do parque, das vias públicas e das casas têm fronteiras profundamente marcadas e limites distintos. Ou seja, os animais vivem no interior dos parques e, do ponto de vista desses humanos, é lá que eles devem permanecer. Já as pistas de corrida e calçadas que circundam as áreas verdes dos parques são lugares de circulação humana e não podem ser "invadidas" pelos macacos. Transgressão ainda mais 
inaceitável é a promovida pelos macacos que saem dos parques e entram em quintais, casas ou escolas.

Desse modo, para os humanos, enquanto o parque é o lugar dos macacos, as avenidas, quintais e casas não o são. Daí justificarem-se as variações tão abruptas nas reações em uns e noutros casos. A partir delas pretende-se contribuir para ampliar as maneiras de descrever e de imaginar as relações híbridas que constituem, em certa medida, aquilo que chamamos de cidade. E, aqui, sem ter a pretensão de esgotar os sentidos e possibilidades de entendimento do que seja a cidade ou do que constitui o urbano, torna-se relevante enfatizar que um dos desafios colocados por essa etnografia implica em delinear alguns problemas relativos ao que significa pensar sobre as paisagens urbanas a partir de perspectivas que consideram seus habitantes não-humanos, inclusive os animais silvestres, como especificamente os macacos-prego, enquanto pertencentes a esses contextos e legítimos habitantes desses espaços.

\section{Os Macacos-prego, a primatologia e o Paraná}

As interações entre humanos e outros primatas têm se acentuado nas últimas cinco décadas de modo intenso e inusitado. Primatas não-humanos estão presentes em contextos científicos, ecológicos, sociais e turísticos e têm sido tema de acalorados debates jurídicos, políticos, simbólicos, filosóficos e acadêmicos, produzindo impactos de múltiplo matiz.

Nessa direção, observa-se que os chimpanzés estão no topo da lista das espécies de primatas que têm fortemente contribuído para a constituição de um Outro não-humano, suficientemente representativo e carregado de significados e, por isso, tem capitaneado os debates sobre a atribuição da condição de "pessoa" a animais não-humanos, o reconhecimento de direitos e a capacidade de reproduzir cultura. No Novo Mundo, os macacos-prego (Cebus) são reconhecidos como os mais próximos dos chimpanzés em termos de comportamento social, inteligência e capacidade cognitiva (Visalberghi \& McGrew, 1997). 
Dentre as muitas espécies de primatas as quais os primatólogos têm se dedicado a estudar o comportamento, há uma de particular interesse: o Cebus apella, Capuchin monkey em termos anglo-saxões devido às cores, distribuição e formato dos pelos que circundam suas cabeças, e que faz lembrar os capuzes dos monges capuchinhos ou, ainda, como preferem os primatólogos brasileiros, macaco-prego. Esta pequena criatura é o primata do Novo Mundo cujo comportamento e inteligência mais tem surpreendido a comunidade científica internacional (Ferreira et al., 2002, Perry, 2006; Fragaszy, Visalberghi \& Fedigan, 2004).

Cebus apella é a antiga denominação (Silva Jr., 2001) usada para o animal conhecido no Brasil como macaco-prego. Atualmente, várias ex sub-espécies de Cebus têm adquirido o status de espécies, à medida em que se acumula mais conhecimento sobre elas. O macaco-prego (Cebus apella) é um primata da família Cebidae, encontrado na América do Sul, principalmente em florestas tropicais e atlânticas, mas também em campos e cerrados, nos territórios que vão da Colômbia à Argentina (Auricchio, 1995). Possui grande capacidade adaptativa e, por isso, pode ser encontrado também em cativeiros, parques, zôos e centros de triagem (Rodrigues et al., 2010). Dentre as espécies conhecidas do gênero Cebus, o Cebus apella é considerado, atualmente, o que possui habilidades cognitivas mais desenvolvidas (Auricchio, 1995).

O macaco-prego é diurno, arborícola, ágil, onívoro (alimenta-se principalmente de frutos, nozes, sementes, flores, insetos, ovos e pequenos vertebrados). Atinge, no máximo, $60 \mathrm{~cm}$ de comprimento e 3,5 kg. Macacos-prego vivem em grupos de 5 a 40 indivíduos onde são observados comportamentos cooperativos significativos e um prolongado (e decisivo) cuidado alomaterno ${ }^{3}$ (Carminatti, 2009). O Cebus é o único primata neotropical que frequentemente utiliza ferramentas em condições naturais como rochas para quebrar frutos encapsulados ou cavar raízes e gravetos para obter mel ou para escavar e pescar insetos.

\footnotetext{
${ }^{3} \mathrm{O}$ cuidado alomaterno é praticado por alguém distinto da mãe biológica que assume o atendimento das necessidades de um filhote temporariamente. Tal cuidado pode ser praticado tanto por machos quanto por fêmeas e é encontrado em espécies sociais, inclusive os humanos. Para mais informações ver Hrdy (2001).
} 
A constatação de que os macacos-prego possuem cérebro grande em relação ao tamanho de seu corpo e longa expectativa de vida, somados ao uso de ferramentas e aos comportamentos relativos à partilha de comida entre os membros do grupo (Visalberghi \& Fragaszy, 1990, Visalberghi \& McGrew, 1997) reforçam os indícios sobre a complexidade de seu comportamento. Os vários registros de utilização de ferramentas correspondem a comportamentos que se reproduzem em dinâmicas inter-geracionais, o que tem levado os macacos-prego a serem comparados aos chimpanzés em termos de inteligência e de habilidades de aprendizado (Ferreira et al. 2002). Tais semelhanças têm transformado os macacos-prego em protagonistas na produção de modelos para análise da evolução da vida social e dos mecanismos cognitivos (Parr et al., 1997).

Passos et al. (2007) assinalam o quanto a prática da primatologia é recente no sul do Brasil. Nessa direção observam que, apesar de alguns esforços representativos, muito pouco se sabe sobre a população de macacos do estado do Paraná e sua distribuição. O rigoroso trabalho de mapeamento de Passos et al. (2007) reforça as informações sobre a existência de uma significativa população de Cebus nigritus no estado distribuída de norte a sul e do litoral para o oeste ${ }^{4}$.

O levantamento de Passos et al. (2007) aponta a existêcia de 60 ocorrências de Cebus nigritus em 44 municípios do Paraná. Em 15 Unidades de Conservação (UC's) foi confirmada a existência. De fato, essa espécie está entre as "mais facilmente encontradas em fragmentos de florestais do estado do Paraná" (Passos et al., 2007 apud Rocha, 2001) e parece conseguir sobreviver em áreas tão pequenas quando tem acesso a pomares e roças das vizinhanças. Isso faz com que, apesar de todo o valor agregado aos macacos-prego a partir das pesquisas científicas, eles sejam encarados como praga agrícola em certas regiões o que sugere uma ameaça futura para suas vidas que não pode ser desconsiderada.

Assim, apesar de toda a mobilização de grandes primatólogos em favor do reconhecimento das grandes capacidades cognitivas e das habilidades sociais dos macacosprego, em Maringá, a presença desses animais no Parque do Ingá, (Passos et al., 2007), no Parque Florestal dos Pioneiros - Borba Gato e no Horto Florestal (Bovo \& Amorim, s.d.) tem sido tratada, nos últimos anos, como um problema. Declarações públicas de autoridades e jornalistas, através da imprensa, têm enfatizado que o aumento da população

\footnotetext{
${ }^{4}$ http://www.icb.ufmg.br/zoo/primatas/cebus_map.htm BDGeoprim, 2002.
} 
de macacos-prego que habita os parques da cidade é um problema e sugere o remanejamento e a vasectomia dos machos alfa restantes.

\section{Os Macacos-prego e a cidade verde}

Os habitantes de Maringá, também conhecida como Cidade Verde, parecem aceitar, de um modo geral e de bom grado esse apelido. Consideram-se, no senso comum, os afortunados moradores de uma cidade tida como uma das mais arborizadas do mundo sem, contudo, considerar as profundas carências do município em relação à gestão dessas áreas verdes e de sua extensão à periferia (Bovo, 2009). A grande imprensa fez circular em âmbito nacional há alguns anos atrás matérias que enfatizavam associações entre as extensas áreas verdes da cidade e sua potencialmente alta qualidade de vida. As cento e quatro praças e os nove parques (Bovo, 2009) e o plantio de árvores segundo seu Plano Diretor sinalizam, para muitos, a paixão dos moradores da cidade pelas árvores.

Contudo, além dos significativos problemas específicos das áreas verdes da Cidade Verde, é importante destacar que as mesmas não são constituídas exclusivamente por plantas, árvores, terra e grama. Uma parcela delas, especificamente alguns parques e hortos, são também habitados por animais que, muitas vezes, não reconhecem limites, portões ou muros como limitadores de seus movimentos e deslocamentos.

Os parques são, por princípio, espaços de "natureza preservada", contida e administrada segundo as regras do poder público dentro das cidades. Além de encerrarem, em si, conflitos profundos entre os domínios da natureza e da cultura, a manutenção dos parques em seu formato definido por humanos depende da habilidade para gerenciar a natureza que escapa de seus limites e se manifesta nos espaços de cultura onde ela não é desejada porque a natureza não reconhece os muros como limites sociais que se expressam simbolicamente através da cultura (Leach, 1978), ou, ao menos, não o fazem do modo esperado pelos humanos que também partilham esses espaços. Isso foi também verificado em relação aos macacos-prego que vivem nos parques de Maringá. 
Esses primatas são considerados um problema pelo poder público municipal porque as populações crescem "demais", demandam altos custos de manutenção, não permanecem dentro dos limites das áreas verdes a eles destinadas, estabelecidas pelos humanos, e se deslocam para casas e avenidas dos arredores para explorar, pegar objetos, obter comida e costumam gerar reações intensas dos moradores, seja de apego, medo ou, mesmo, irritação (O diário, 2008, 2010, 2014).

A presença de macacos-prego em Maringá foi registrada no Parque do Ingá (Passos et al., 2007), no Parque Florestal dos Pioneiros - Borba Gato e no Horto Florestal (Bovo \& Amorim, s.d.). No Paraná, há outros casos nos quais um parque que abriga uma população de macacos-prego inserido num núcleo urbano que, segundo registros feitos pela grande imprensa, também geram situações de conflito como em Foz do Iguaçu, Cascavel, Cambé e Cianorte ${ }^{5}$.

Assim, diante dos conflitos registrados entre humanos e macacos-prego em Maringá e da nascente primatologia no estado do Paraná (Passos, 2014), esse texto também visa, a partir de uma reflexão que considere ambos como pertencentes e legítimos moradores do espaço urbano, esboçar reflexões sobre essas relações interespecíficas que ofereçam alguns subsídios para desdobramentos futuros no âmbito das políticas públicas voltadas a questões ambientais, bem como registrar algumas vivências constituídas a partir das relações entre os humanos, os macacos e o lugar. Nesse sentido, o texto pode oferecer elementos para análises sobre o presente e o futuro dessas relações entre humanos e macacos-prego num estado, como o Paraná, marcado por uma destruição recente e crescente de sua cobertura vegetal, mas que ainda abriga espécies que habitam o que resta da mata atlântica no planeta e que se colocam em crescente contato com a mudança da paisagem associada à presença humana e acompanhada pela expansão da agroindústria e do agronegócio e por uma complexa, recente e crescente expansão de áreas e atividades urbanas.

Ora, enquanto a expansão agrícola massiva se apresenta como força motriz de ocupação dos espaços rurais do Brasil associada, por exemplo, à produção de soja e, ao se estabelecer, afeta e modifica profundamente a configuração de toda a paisagem ameaçando a fauna e, inclusive, nossos protagonistas macacos-prego, como ocorre no sul do Piauí (Rapchan \& Neves, 2016 - artigo submetido), os incômodos causados aos humanos pelos

\footnotetext{
${ }^{5} \mathrm{http}$ //ambientes.ambientebrasil.com.br/florestal/programas_e_projetos/projeto_macaco-prego.html
} 
macacos não recebem atenuantes a partir da consideração de que ou os macacos são habitantes nativos das matas transformadas em parques pelos humanos ou os macacos se deslocaram de outros habitats que foram modificados ou destruídos pela expansão agroindustrial. Aliás, uma das características marcantes do comportamento dos macacosprego é exatamente sua extrema flexibilidade.

\section{Quando até um macaco incomoda muita gente...}

As primeiras observações de pesquisa foram feitas a partir dos funcionários e administradores do Parque do Ingá, que é vinculado à Secretaria Municipal do Meio Ambiente do Município de Maringá. Esses funcionários são os responsáveis pelo trato e manejo dos macacos-prego distribuídos por três áreas verdes da cidade: o próprio Parque do Ingá que tem uma pequeníssima população de animais confinados, o Bosque dos Pioneiros e o Parque Borba Gato cujas populações são muito maiores.

A primeira impressão que se tem, a partir desses funcionários, é que a grande quantidade de trabalho e os custos relacionados ao manejo dos animais são considerados altos demais. Apesar de haverem variações individuais de empatia, simpatia ou indiferença aos animais, verifica-se uma atitude comum em favor da necessidade de se conter tanto o crescimento da população de macacos-prego quanto o reconhecimento de que a saída dos animais das áreas verdes para os lugares habitados ou ocupados por humanos, nas imediações e vizinhanças, é um problema sério e deve ser contido pelas autoridades municipais. Nesses casos, situações de conflito ocorridas em municípios vizinhos são sempre lembradas como emblemáticas da ferocidade dos macacos e da dificuldade de lidar com eles.

Ao mesmo tempo, os registros feitos pela imprensa local oferecem material instigante relacionado aos encaminhamentos municipais em relação os animais e que são diretamente ligadas à proposição de fragmentação das populações de macacos que vivem no município seguidas de iniciativas em favor do remanejamento para reservas ambientais em outros municípios e da esterilização dos macacos-prego que permanecerem nas áreas verdes maringenses. Ainda não foi possível entrevistar as autoridades municipais em relação a isso, nem observá-las em situações relacionadas à tomada de decisões em relação 
aos macacos-prego da cidade. Essa parte do trabalho está prevista para a continuação dessa pesquisa.

Por fim, nas observações já feitas sobre os contatos entre humanos e macacos-prego no entorno do Horto e do bairro Borba Gato foi observar dois padrões gerais de contato entre os humanos e os macacos. Um deles está relacionado a contextos de lazer, onde humanos dispostos a passear com os filhos pequenos, a praticar corrida ou a pescar e confraternizar nos pesqueiros da cidade, se encontram com os macacos e estabelecem com os mesmos uma relação ambígua, que oscila entre interesse, empatia e curiosidade, de um lado, e irritação devido ao fato de os macacos parecerem hostis ou estarem dispostos a carregar rapidamente qualquer objeto ou alimento que desperte interesse. Contudo, parecem prevalecer os comportamentos não agressivos em relação aos animais, bem como os comentários mais amistosos.

Em relação às relações estabelecidas com os moradores do entorno das duas áreas (Horto e Borba Gato), verifica-se que, apesar de exibirem o mesmo caráter ambíguo em relação aos macacos, há um predomínio das atitudes, emoções e discursos de caráter negativo. Ao mesmo tempo, percebe-se variações nessas relações em relação à representações sobre a natureza ou mesmo vínculos mais superficiais ou mais profundos com os primeiros processos de ocupação e formação da área urbana do município.

Nesse sentido, o texto que informa a adoção da vasectomia como estratégia da prefeitura para conter o aumento da população de macacos, apresentado pelo Jornal Hoje da TV Globo em 09/08/2014 é exemplar:

Em bandos, os macacos vivem tranquilos nas matas nativas da cidade. Como eles saem da mata frequentemente, não é difícil ver que os bandos estão ficando cada vez maiores. O problema é que os macacos não têm predador natural, por isso o bando está aumentando.

(...)

Segundo cálculos do município, nos últimos anos, os bandos aumentaram em torno de $30 \%$, passando de 200 para 260 macacos. Se a mata fica pequena, eles invadem mais o espaço das pessoas. "Tem que desviar, tem que mudar o caminho às vezes", relata a estudante Heloisa Andrade.

Os macacos tomam conta das calçadas, ocupam as pistas de caminhada e sobem até nos carros, mas mesmo assim, encantam os moradores. "Eu acho eles fofinho até, mas de longe", diz a estudante Laira Tamarinho. (http://g1.globo.com/jornalhoje/noticia/2014/08/maringa-quer-fazer-vasectomia-em-macacos-para-reduzirsuperpopulacao.html). 


\section{Macacos em manchete}

No caso específico das relações entre humanos e macacos-prego em Maringá, podese afirmar que, por meio dos registros elaborados pelos viéses da grande imprensa escrita e televisiva coletados entre 2002 e 2014, há fortes indícios de que ela seja conflituosa e o tom dominante dos discursos é o que enfatiza os aspectos negativos do crescimento da população de macacos na cidade. Tal crescimento, por sua vez, ser diretamente associado às dificuldades de conter os macacos em seu "espaço devido", isso é, os limites dos parques. Assim, a travessia das que os macacos-prego efetuam, e que só tem sentido efetivo para os humanos porque são barreiras socioculturais, afinal são muros e cercas, é interpretada pelos meios de comunicação como um comportamento que, automaticamente, fragiliza os humanos mesmo quando eles são responsabilizados.

Em 2002, o site do jornal $O$ diário de Maringá online publicou um artigo que faz referências negativas ao comportamento da população maringaense por aproximar-se excessivamente dos macacos e porque "existem famílias inteiras que chegam ao parque com sacolas cheias de guloseimas, trazendo alimentos industrializados, criando nos animais péssimos hábitos alimentares". "Essas famílias (continua o jornal) costumam trazer seus filhos para o parque, e acabam ensinando-os a transgredirem algumas regras, aquelas evidenciadas nas placas que sinalizam: "não alimentem os animais"” ( $O$ diário de Maringá online, "Macacos continuam a receber alimentos", 2002). Tais julgamentos, por sua vez, são também reforçados por algumas entrevistas transcritas na reportagem.

Em 2007, o mesmo jornal publica outra reportagem com o título "Não brinque com os macacos". O texto, dessa vez, avança na análise associando os alimentos que os "visitantes" oferecem aos macacos com possíveis reações de "ataque" (ou defesa?) que alguns visitantes "inocentes", em posse de suas câmeras fotográficas, teriam sofrido durante passeio (e não invasão!) do espaço de reserva florestal destinado a esses animais. Aqui, a questão da paisagem como território reaparece. Só que, dessa vez, não são os macacos que, ao sair do parque, "invadem" a cidade, mas são os humanos que são retratados como "inocentes" "visitantes" e não como transgressores do espaço reservado aos animais silvestres. Assim, como as fronteiras são humanas, eles podem atravessá-las quando bem entendem, o que parece não ser válido para os macacos. 
No ano de 2008, o Diário de Maringá online publica: "Macacos dão adeus ao Horto Florestal" (2008). Antropomorfização forçada, o título ironiza a retirada dos animais como um afastamento desejado pelos humanos já que os macacos-prego são animais traiçoeiros, invadem casas, trazem doenças, e ainda atacam pessoas "inocentes" no interior do parque, e no seu entorno. O artigo segue com a seguinte informação: "Cerca de quarenta macacos serão levados para um reserva particular em Mauá da Serra até abril de 2009” ( $O$ diário, 2008).

Em 2009, o ano esperado, exatamente no mês de abril, quando finalmente a população de macacos-prego "ganharia um novo lar" - supostamente mais seguro para eles e para a população maringaense - algo inusitado, e não esperado, ocorreu: os animais começaram a morrer. Foram ao todo 14, conforme o próprio jornal. De acordo com a primeira das publicações do jornal "O diário" online a respeito do tema, naquele ano, as mortes teriam sido causadas por febre amarela ( $O$ diário, 17/04/2009). Numa edição posterior, do mesmo ano, descartava-se a possibilidade de morte dos animais por febre amarela. Em artigo publicado na sequência (ainda em 2009), sobre as mortes dos macacos pregos em Maringá, a responsabilidade das mortes teria sido transferida para uma doença conhecida como Coreomeningite, doença causada pelo "arenavírus". Conforme as informações contidas nesse artigo "essa doença é bastante comum na América do Norte e na Europa, contudo, é muito rara aqui no Brasil”. Por fim, ainda em 2009 aparece como manchete no jornal $O$ diário online a explicação derradeira para as mortes dos 14 primatas: "Macacos mortos em abril no Parque do Ingá tinham herpes".

Nos anos seguintes, o incômodo pela presença de macacos-prego continuou a ser registrado pela imprensa. Em entrevista ao Jornal da emissora Bandeirantes ${ }^{6}$ publicada no Youtube em junho de 2012, a Gerente do Meio Ambiente da Secretaria do Meio Ambiente enfatiza os problemas enfrentados pelo município em relação ao aumento da população de macacos-prego do Parque do Ingá e no Horto Florestal.

Segundo a reportagem, os macacos estão "mal acostumados" devido aos alimentos oferecidos pelos visitantes. Por isso, estariam ocorrendo alterações nas taxas de reprodução, nos padrões de alimentação e no comportamento desses animais. A solução para o problema, segundo a coordenadora da equipe que realizou contagem e monitoramento dos

\footnotetext{
${ }^{6} \mathrm{http}: / /$ www.youtube.com/watch?v=KQ_vzVWU7Ok
} 
macacos-prego do município em 2007 é a retirada dos animais das áreas urbanas e a vasectomia dos machos alfa dos grupos restantes, o que iria reduzir o crescimento populacional dos animais, considerando que os macacos-prego não têm predadores naturais nessa região.

Os desdobramentos relacionados à retirada de um parcela da população dos macacos-prego dos parques e a realização de vasectomias demandam um outro recuo temporal em relação às fontes jornalísticas.

Dentre as reportagens de jornal consultas, uma das que melhor enfatizou a assimetria maniqueísta das relações entre humanos e macacos-prego, vitimizando os primeiros, recebeu o título "Macacos 'invadem' colégio em busca de comida". Apesar do incômodo produzido pela manchete o resultado do artigo é um tanto menos desastroso, porque mostra o que (e como) algumas pessoas, incluindo alunos e funcionários da escola pensam sobre a relação entre os humanos e os animais no mesmo espaço. Segundo as informações contidas neste artigo: "entre os alunos, os animais fazem o maior sucesso, são apreciados, não incomodam; já entre os professores, a situação é um pouco diferente: 'temos que ficar com as janelas e as portas fechadas, o calor é insuportável, perdemos a nossa privacidade, pois, os animais invadem o lugar e roubam os nossos alimentos"” ( $O$ diário, 2010).

Por fim, em anos recentes, a contenção dos macacos em função dos argumentos relacionados aos riscos à saúde pública que eles representam foi ganhando força. Registros epidemiológicos da presença dos vetores transmissores da febre amarela e da leishmaniose foram feitos tanto no Horto Florestal, que pertence à Companhia Melhoramentos do Norte do Paraná quanto no Conjunto Residencial Borba Gato, associados à presença de macacos nesses locais através de pesquisa feita em 2001 (Santos et al., 2009). Em 2014, a Secretaria Municipal do Meio Ambiente (SEMA) obteve autorização do Instituto Chico Mendes para a Conservação da Biodiversidade (ICMBio) e do Sistema de Autorização e Informação em Biodiversidade (Sisbio) para desenvolver projeto-piloto que irá realizar vasectomias nas populações de macacos do Horto Florestal, do Parque Borba Gato e do Parque dos Pioneiros (O Diário, 10/11/2014). Os transtornos causados à população humana tais como a entradas nas casas, os acidentes de trânsito associados à presença de macacos na pista e algumas mordidas parecem ter sido, finalmente, contidos por outros animais não-humanos: 
os microorganismos. E, assim, os macacos estão sendo eliminados dessas paisagens urbanas.

\section{$O$ anti-dualismo como hipótese antropológica: nem humano, nem animal}

A antropologia sociocultural, desde sua instituição como disciplina no rol da modernidade, tem enfrentado os desafios de equacionar um humano, universal, diante da diversidade cultural, local e específica. Isso significou, entre outras coisas, o enfrentamento de questões relacionadas às escalas social e animal do pensar teoricamente sobre o humano. Soluções e distensões em relação aos alcances da influência da vida coletiva e da natureza foram sendo apresentadas ora como sobreposições, ora como oposições.

No pensamento ocidental, as concepções do que é um animal não-humano estão carregadas de preconceitos intelectuais e emocionais. $\mathrm{O}$ animal é pensado como um ser inferior e deficiente em relação aos humanos. Daí, a definição de humano como negação da condição animal é, em si, um paradoxo (Ingold, 1994).

Ingold (1994) sinaliza que, como organismos vivos, tanto os humanos quanto todos os outros são a expressão de uma miríade de diferenças marcadas por gradações sutis. Assim, uma dada espécie é constituída por um conjunto de organismos que possui variações até um determinado alcance. A partir daí, os indivíduos identificáveis pertencem aos limites de outra espécie. Seria, segundo ele, essa variação o fator essencial da distinção entre os seres vivos e os objetos inanimados.

Desse modo, Ingold sugere que a cultura e os humanos não sejam pensados em oposição à natureza, mas a partir e em relação a ela, numa perspectiva inclusiva e não exclusiva. Desse modo, sua proposição é que a condição humana não seja atribuída nem exclusivamente à natureza, nem exclusivamente à cultura. Propõe uma terceira via que aborde o humano como produtos de genes, ambiente e cultura (Ingold, 2001: 237).

Nesse sentido, Ingold (2015) propõe uma aproximação entre a biologia e a antropologia a partir da adoção da perspectiva tudo o que está em relação: animais e humanos, seres vivos e paisagem partilham uma história comum a qual, por sua vez, engloba, inclusive, a ideia de evolução e supera a dicotomia entre genótipo e fenótipo. Daí a ênfase na ideia de construção como um processo circular no qual a ideia e o material 
estão em relação, de um modo tal que um nem outro sejam fins em si, nem sejam conceitualmente superiores nem subordinados um em relação ao outro.

Por várias razões, algumas louváveis e outras não, a aproximação entre humanos e primatas não-humanos em nossa sociedade parece ser inexorável e irreversível. Verifica-se, nas últimas décadas, um movimento crescente de aumento da visibilidade no que tange às interações entre humanos e outros primatas. A consciência da complexidade atrelada à presença de primatas não-humanos em contextos urbanos, rurais, turísticos e em reservas ecológicas, parques e laboratórios têm se acentuado e intensificado. Uma das consequências disso são os debates crescentes em campos como o das políticas ambientais, do direito, da filosofia, da ciência, das artes.

Verifica-se, também, sinais de um processo profundo de transformação do conhecimento acumulado sobre nossos "parentes mais próximos". Simultaneamente ocorre, ainda, a reformulação das representações e classificações que produzimos sobre eles, o que incide diretamente sobre a formulação de ideias sobre seus direitos (Armstrong \& Botzler 2003, Cavalieri \& Singer 1995, Lestel 2004, Spruit 1995, Sustein \& Nussbaum 2004, Vilmer 2010). Estão, também, em curso mudanças sobre a consciência de nossas responsabilidades e compromissos com eles na medida em que percebemos que partilhamos territórios ou características. Nesta direção, a primatologia tem se transformado profundamente (Dukelow, 1999), mas setores da sociedade civil também acompanham tais mudanças.

Nesse sentido, abre-se espaço para considerar que as interconexões entre humanos e outros primatas sejam vistas como algo mais do que simplesmente rupturas de um "estado natural" mas, principalmente, como uma direção potencial para o entendimento de relações que, por muitas vias, tornam-se cada vez mais próximas e complexas (Fuentes \& Hockings 2010).

Sob essa inspiração, o retorno às relações entre os macacos-prego, os humanos e os parques em Maringá se recoloca sob o signo da interação tensa, tumultuada e conflituosa do espaço da cidade. As fronteiras e limites da paisagem demarcados pelos humanos, que indicam os lugares adequados e os lugares proibidos aos macacos-prego, parecem concentrar o núcleo dos enfrentamentos. Isso porque, ironicamente, a flexibilidade comportamental e cognitiva aliada à disposição em explorar novos ambientes são 
características marcantes tanto dos macacos-prego quanto dos humanos. Primatólogos ao redor do mundo têm se voltado ao estudo dos macacos-prego no Brasil (Falótico et al. 2016; Visalberghi \& McGrew, 1997), surpresos por suas habilidades e dispostos a comparálos com os chimpanzés e, portanto, aproximá-los da inteligência e da complexidade social humana.

Contudo, tais características recebem valores positivos quando se trata de humanos e valores negativos quando o assunto são os comportamentos dos macacos-prego rotulados como "invasores" dos espaços urbanos e, portanto, humanos em Maringá. Assim, a saída dos macacos dos limites dos parques repercutem em situações problema cujas soluções, como se viu, desembocaram em ações humanas coibitivas e castradoras (nos sentidos metafórico e literal).

\section{Agradecimentos}

Todos os membros do Laboratório de Estudos Evolutivos Humanos (LEEH) da UEM têm uma contribuição importante na elaboração desse manuscrito. Mas, entre eles, gostaria de agradecer especialmente a Eliane Cristina Godoy que, expressando genuína generosidade intelectual, indicou fontes jornalísticas e ofereceu comentários e insights sobre as mesmas que deram densidade a muitas das observações de campo.

\section{Referências}

ARMSTRONG, S.; BITZLER, R.G. (eds.). 2003. The Animal Ethics Reader, London: Routledge. ASQUITH, P. 2011. Commentary: Of Bonds and Boundaries: What is the Modern Role of Anthropomorphism in Primatological Studies?, American Journal of Primatology 73, p. 238-244. AURICCHIO, P. 1995. Primatas do Brasil, São Paulo: Terra Brasilis, p. 13-33.

BECKERT, C. 2003. Dilemas da Ética Ambiental: Estudo de um Caso, Revista Portuguesa de Filosofia 59(3), p.675-687.

BOVO, M. C. 2009. Áreas verdes urbanas, imagem e uso: Um estudo geográfico sobre a cidade de Maringá-PR, tese de doutorado, Unesp - Presidente Prudente.

BOVO, M. C. \& AMORIM, M. C. de C. T. s.d. Análise e diagnóstico dos Parques Urbanos em Maringá - PR. s.l.

CARMINATTI, M. O. F. 2009. Efeitos da paridade da mãe e do sexo do filhote sobre o estilo de cuidado materno e o desenvolvimento de filhotes de macacos-prego (Cebus sp), Dissertação de Mestrado, Instituto de Psicologia, Universidade de São Paulo. 
CAVALIERI, P. \& SINGER, P. 1995. "The Great Ape Project” in Corbey, R. \&Theunissen, B. (eds.), Ape, Man, Apeman: Changing Views since 1600, Leiden: Dept. of Prehistory, Leiden University, p. 367-376.

CORBEY, R. \& THEUNISSEN, B. (eds.), 1995. Ape, Man, Apeman: Changing Views Since 1600. Leiden: Dept. of Prehistory, Leiden University.

DE CERTEAU, M.; GIARD, L. \& MAYOL, P. 1997. A invenção do cotidiano 2, Petrópolis: Vozes. DUKELOW, R. W. 1999. Invited editorial: reflections on a century of primatology, American Journal of Primatology 49, p. 129-32.

FALÓTICO, T.; INABA, A.; McGREW, W. C.; OTONI, E. 2016, Vertical bipedal locomotion in wild bearded capuchin monkeys (Sapajuslibidinosus). Primates, p.1-8, May 2016.

FELIPE, S.T. 2009. Antropocentrismo, sencientismo e biocentrismo: Perspectivas éticas abolicionistas, bem-estaristas e conservadoras e o estatuto de animais não-humanos. Páginas de Filosofia 1(1), p. 2-30.

FERREIRA, R. et al. 2002. Bird predation and prey-transfer in brown capuchin monkeys (Cebus apella), Neotropical Primates 10(2), p. 84-91.

FUENTES, A. \& HOCKINGS, K. J. 2010, The Ethnoprimatological Approach in Primatology, American Journal of Primatology 72(10), p. 841-47.

HARAWAY, D. 1991. Simians, Cyborgs and Women: The Reinvention of Nature. New York: Routledge and London: Association Books.

HRDY, S.B. 2001. Mãe Natureza. Uma Visão Feminina da Evolução. Rio de Janeiro: Campus.

IBGE. 2015. Censo Demográfico. Brasil.

INGOLD, T. 1994. Humanity and animality. In: Ingold, T. (Org.). Companion encyclopedia of anthropology. London: Routledge, p. 14-32.

INGOLD, T. 2001.The use and abuse of ethnography. Behavioral and Brain Sciences, 24, 2, p. 337.

INGOLD, T. 2015. Estar vivo. Ensaios sobre Movimento, Conhecimento e Descrição, Petrópolis: Vozes.

LATOUR, B. 2000. A Well-Aticulated Primatology - Reflexions of a Fellow-Traveler. In Strum, S. and Fedigan, L. (eds.). Primate Encounters, Chicago: University of Chicago Press, p. 358-381.

LEACH, E. 1978. Cultura e Comunicação. Rio de Janeiro: Zahar.

LESTEL, D. 2004. L'Animal Singulier, Paris: Seuil.

LESTEL, D. 2008. Le communautés hybrides, Sciences humaines 6 (194).

MENDONÇA, L.E.T. , Souto, C.M., ANDRELINO, L.L., SOUTO, W.M.S., VIEIRA, W.L.S., ALVES, R.R.N., 2011. Conflitos entre pessoas e animais silvestres no Semiárido paraibano e suas implicações para conservação. Sitientibus série Ciências Biológicas 11(2), p. 185-199.

PARR, L. A. et al. 1997. Grooming down the hierarchy: Allogrooming in captive brown capuchin monkeys, Cebus apella, Animal Behaviour 54(2), p. 361-67.

PASSOS, F. C. (Org.), 2014, A Primatologia no Brasil 13. 1. ed. Curitiba: Sociedade Brasileira de Primatologia, 2014.

PASSOS, F. C.; MIRANDA, J.M.D.; AGUIAR, L.M.; LUDWIG, G.; BERNARDI, I.P.; MORORIOS, R.F. 2007. Distribuição e Ocorrência de Primatas no Estado do Paraná, Brasil.In BiccaMARQUES, J.C. (ed.). A Primatologia no Brasil 10. Porto Alegre: Sociedade Brasileira de Primatologia.

PERRY, S. 2006. What cultural primatology can tell anthropologists about the evolution of culture, Annual Review of Anthropology 35, p. 171-190.

PRIORI, A.; POMARI, L.R.; AMÂNCIO, S.M. e IPÓLITO, V.K. 2012. História do Paraná: Séculos XIX e XX. Maringá: Eduem.

RAPCHAN, E. S. 2005. Chimpanzés possuem cultura? Questões para a antropologia sobre um tema 'bom para pensar'. Revista de Antropologia 48(1), p. 227-280.

RAPCHAN, E. S. 2010. Sobre o comportamento de chimpanzés: O que antropólogos e primatólogos podem ensinar sobre o assunto?, Horizontes Antropológicos 16(33), p. 227-266. 
RAPCHAN, E.S. \& NEVES, W.A.2016. Famílias Híbridas: Camponeses, Primatólogos e MacacosPrego no Cerrado Piauiense. [submetido].

RAPCHAN, E. S. \& NEVES, W. A. 2005. Chimpanzés não amam! Em defesa do significado, Revista de Antropologia 48(2), p. 649-698.

RICARDO, F. (org.) 2004. Terras Indígenas \& Unidades de Conservação da natureza: o desafio das sobreposições. São Paulo: Instituto Socioambiental.

RODRIGUES, L. S. F.; ALMEIDA, S. A. C.; RODRIGUES, A. F. S. F. \& PREZOTO, F. 2010. Comportamento e distribuição de um grupo de macacos-prego (Cebus apella Linnaeus, 1758) mantido em cativeiro, CES Revista 24, Juiz de Fora, p. 45-57.

SANTOS, B.S. 2002. Para uma sociologia das ausências e uma sociologia das emergências. Revista Crítica de Ciências Sociais 63, p. 237-280.

SILVA Jr., J. S. 2001. Especiação nos macacos-prego e caiararas, Gênero Cebus Erxleben, 1777 (Primates, Cebidae). Tese de Doutorado, Universidade Federal do Rio de Janeiro, Rio de Janeiro.

SANTOS, D.R.; SANTOS, A.R.; SANTOS, E.S.; OLIVEIRA, O.; POIANI, L.P.; SILVA, A.M., 2009, Observing Diurnal Habits of Nyssomyia whitmani (Diptera: Psychodidae) in the Urban Area of Maringá, Paraná, Brazil, Epidemiol. Serv. Saúde 18(3), Brasília, p. 227-236, jul-set 2009.

SEGATO, R.L. 2006. Antropologia e direitos humanos: alteridade e ética no movimento de expansão dos direitos universais. Mana 12(1), 2006, p. 207-236.

SPRUIT, I. 1995. "On Declaring Non-human Primate Rights: An Approach to Primate Protection" in Corbey, R. \& Theunissen, B. (eds.), Ape, Man, Apeman: Changing Views since 1600, Leiden: Dept. of Prehistory, Leiden University.

STANFORD, C. B. 2001. The Significant Other, New York: Basic Books.

STRATHERN, M. 2005. Partial Conections, New York: Altamira Press.

STRATHERN, M. 2014. 5. Fora de contexto: as ficções persuasivas da antropologia, $O$ efeito etnográfico e outros ensaios, Cosac Naif.

SUSTEIN, C. R. \& Nussbaum, M. C. 2004. Animal Rights: Current Debates and New Directions, New York: Oxford University Press.

VILMER, J. B. J. 2010. Le critère de la souffrance dans l'éthique animale anglo-saxonne. In Guichet, J.-L.(dir.), Douleur animale, douleur humaine: données scientifiques, perspectives anthropologiques, questions éthiques, Paris: Quae.

VISALBERGHI, E. \& FRAGASZY, D. 1990. Washing-behaviour in tufted capuchin monkeys, Cebus apella, and crabeating macaques, Macaca fascilularis, Animal Behaviour 40(5), p. 829-36.

FRAGASZY, D. M.; VISALBERGHI, E. \& FEDIGAN, L. M. 2004. The complete capuchin: The biology of the Genus Cebus, Cambridge: Cambridge University Press.

VISALBERGHI, E. \& McGREW, W. C. 1997. Cebus Meets Pan, International Journal of Primatology 18(5), p. 677-681.

WARNER, M. 1999. No go the bogeyman: scaring, lulling, and making mock, New York: Farrar, Straus and Giroux.

VERRI Jr., A. A obra de José Augusto Belucci em Maringá, Dissertação de Mestrado. São Paulo: FAU-USP, 2001.

WARNER, M. 1996. From the Beast to the Blonde: On Fairy Tales and Their Tellers, New York: Farrar, Straus and Giroux 


\section{Fontes da Imprensa}

Gazeta do Povo, Fechado há seis anos, Recanto Borba Gato ainda oferece risco de leishmaniose. 19/05/2010. http://www.gazetadopovo.com.br/vida-e-cidadania/maringa/fechado-ha-seis-anosrecanto-borba-gato-ainda-oferece-risco-de-leishmaniose-01 knoqpi4d0s110zctps7jdqm http://maringa.odiario.com/maringa/2014/04/maringa-tera-projeto-de-controle-populacional-demacacos-pregos/824691/

O Diário, 10/11/2014. (http://maringa.odiario.com/maringa/2014/11/institutos-aprovam-projeto-demanejo-populacional-de-macacos-pregos-de-maringa/1226953/)

http://maringa.odiario.com/maringa/2002/02/macacos-continuam-a-receber-alimentos/31519/ http://maringa.odiario.com/maringa/2007/02/nao-brinque-com-os-macacos/174872/ http://maringa.odiario.com/maringa/2008/12/macacos-dao-adeus-ao-horto-florestal/206955/ http://maringa.odiario.com/maringa/2009/04/sobe-para-11-os-macacos-mortos-em-maringasintomas-indicam-febre-amarela/215502/

http://maringa.odiario.com/maringa/2009/04/secretaria-da-saude-descarta-que-febre-amarela-tenhacausado-a-morte-de-macacos/216049/

http://maringa.odiario.com/maringa/2009/04/instituto-adolfo-lutz-descarta-morte-de-macacos-porfebre-amarela/216083/

http://maringa.odiario.com/maringa/2009/04/o-que-esta-matando-os-macacos-no-parque-doinga/216101/

Recebido em: 28/10/2016.

Aprovado em: 05/12/2016. 